\title{
The effects of shoulder arthroscopy on ultrasound image quality of the interscalene brachial plexus: a pre- procedure vs post-procedure comparative study
}

Jason K. Panchamia ${ }^{1 *}$, Ram Jagannathan², Bridget P. Pulos ${ }^{1}$, Adam W. Amundson ${ }^{1}$, Joaquin Sanchez-Sotelo ${ }^{3}$, David P. Martin ${ }^{1}$ and Hugh M. Smith ${ }^{1}$

\begin{abstract}
Background: Fluid extravasation from the shoulder compartment and subsequent absorption into adjacent soft tissue is a well-documented phenomenon in arthroscopic shoulder surgery. We aimed to determine if a qualitative difference in ultrasound imaging of the interscalene brachial plexus exists in relation to the timing of performing an interscalene nerve block (preoperative or postoperative).

Methods: This single-center, prospective observational study compared pre- and postoperative interscalene brachial plexus ultrasound images of 29 patients undergoing shoulder arthroscopy using a pretest-posttest methodology where individual patients served as their own controls. Three fellowship-trained regional anesthesiologists evaluated image quality and confidence in performing a block for each ultrasound scan using a five-point Likert scale. The association of image quality with age, gender, BMI, duration of surgery, obstructive sleep apnea, and volume of arthroscopic irrigation fluid were analyzed as secondary outcomes.
\end{abstract}

Results: Aggregate preoperative mean scores in quality of ultrasound visualization were higher than postoperative scores (preoperative 4.5 vs postoperative $3.8 ; p<.001$ ), as was confidence in performing blockade based upon the imaging (preoperative 4.8 vs postoperative $4.2 ; p<.001$ ). Larger BMI negatively affected visualization of the brachial plexus in the preoperative period ( $p<0.05$ for both weight categories). Patients with intermediate-high risk or confirmed obstructive sleep apnea had lower aggregate postoperative mean scores compared to the low-risk group for both ultrasound visualization (3.4 vs 4.0; $p<.05$ ) and confidence in block performance (3.8 vs 4.4; $p<.05$ ).

Conclusion: Due to the potential reduction of ultrasound visualization of the interscalene brachial plexus after shoulder arthroscopy, we advocate for a preoperative interscalene nerve block when feasible.

Trial registration: ClinicalTrials.gov (NCT03657173; September 4, 2018).

Keywords: Brachial plexus block, Arthroscopy, Ultrasonography, Extravasation of diagnostic and therapeutic materials

\footnotetext{
* Correspondence: Panchamia.Jason@mayo.edu

'Department of Anesthesiology and Perioperative Medicine, Mayo Clinic, 200

First St SW, Rochester, MN 55905, USA

Full list of author information is available at the end of the article
}

\section{$\triangle B M C$}

(c) The Author(s). 2021 Open Access This article is licensed under a Creative Commons Attribution 4.0 International License, which permits use, sharing, adaptation, distribution and reproduction in any medium or format, as long as you give appropriate credit to the original author(s) and the source, provide a link to the Creative Commons licence, and indicate if changes were made. The images or other third party material in this article are included in the article's Creative Commons licence, unless indicated otherwise in a credit line to the material. If material is not included in the article's Creative Commons licence and your intended use is not permitted by statutory regulation or exceeds the permitted use, you will need to obtain permission directly from the copyright holder. To view a copy of this licence, visit http://creativecommons.org/licenses/by/4.0/ The Creative Commons Public Domain Dedication waiver (http://creativecommons.org/publicdomain/zero/1.0/) applies to the data made available in this article, unless otherwise stated in a credit line to the data. 


\section{Background}

Ultrasound guided interscalene nerve blockade (ISB) is considered the gold standard regional anesthetic technique for providing analgesia after shoulder arthroscopy, shoulder arthroplasty, and other upper extremity procedures $[1,2]$. ISB can be performed before or after surgery; however, the optimal timing for ISB remains unknown. Practice patterns may be influenced by historical precedent, institutional protocols, and need for postoperative neurological assessment, among other considerations. Increased neck circumference and airway edema have been observed after arthroscopic shoulder procedures, suggesting extracapsular fluid extravasation and absorption into adjacent tissues may affect tissue planes of the neck where ISB is performed [3]. Complications of ISB, although rare, include major vascular injury, pneumothorax, brachial plexus palsy, nerve injury and phrenic nerve paresis. Thus, anatomical visualization of relevant structures is critical to its safe performance [4-6]. Considering implications of arthroscopic shoulder surgery - acute inflammation, muscle mobilization, and large volume irrigation - there is a deficiency of data regarding the impact of the arthroscopic surgery on ultrasound image quality during ISB. Subsequently, it is unknown whether the timing of the peripheral nerve block, with respect to the surgical procedure, impacts block efficacy and safety. Anecdotally, fellowship trained regional anesthesiologists at our institution who routinely perform ISB in different hospital settings, both before and after surgery, have observed that ultrasound image quality tends to be reduced in the postsurgical setting. Further, patients who do not receive preoperative blockade may be subject to increased perioperative opiate use, increased post anesthesia care unit (PACU) length of stay, and central sensitization to pain [7].

The objective of this study was to determine if a qualitative difference in ultrasound imaging at the interscalene level of the brachial plexus exists before and after arthroscopic shoulder surgery. We hypothesized expert regional anesthesiologists would consistently score preoperative ultrasound scans of the brachial plexus at the interscalene level higher in image quality and have greater confidence in performing ISB, in comparison to postoperative scans at the same level.

\section{Methods}

We conducted a single-group, prospective observational study at a single academic hospital, using a preprocedure vs post-procedure methodology where individuals served as their own controls. This study was approved by our Institutional Review Board (No. 18004131, Mayo Clinic, Rochester, MN, USA) and was registered at ClinicalTrials.gov (NCT03657173). All patients provided written informed consent to participate, and the study protocol was performed in accordance with the relevant guidelines. The reporting of this study adheres to the Strengthening the Reporting of Observational studies in Epidemiology (STROBE) guidelines [8].

\section{Study patients}

All adult patients (age $\geq 18$ years) with an ASA physical classification of I to III scheduled for elective, arthroscopic shoulder surgery were recruited between June 2018 and November 2018. Patients were excluded if they fulfilled any of the following criteria: patient refusal to provide informed consent, cognitive disorder, allergy to study medications, BMI $>40 \mathrm{~kg} / \mathrm{m} 2$, neck circumference $>50 \mathrm{~cm}$, moderate to severe pulmonary disease (use of home oxygen, preoperative $\mathrm{SpO} 2<94 \%$ on room air, forced expiratory volume in $1 \mathrm{~s}<60 \%$ of predicted value), contralateral hemidiaphragm dysfunction, phrenic nerve injury, or a contraindication to regional anesthesia (neuropathy or coagulopathy).

Potential study subjects were identified from the operative calendar of three fellowship-trained orthopedic surgeons who practice at the same institution, use similar operative techniques, and perform a high volume of arthroscopic shoulder procedures. Study recruitment and informed consent occurred during preoperative consultation with the attending anesthesiologist, after the patient agreed to receive preoperative ISB and general anesthesia for an arthroscopic shoulder procedure. A member of the study's research team then reviewed the informed consent documentation, corroborated inclusion/exclusion criteria, and enrolled those eligible for participation.

Patients were admitted to a preoperative procedure room 60 to $90 \mathrm{~min}$ prior to their scheduled surgery. Digital captures of a standardized ultrasound examination of the brachial plexus at the interscalene level were completed by three study personnel, all of whom were fellowship-trained regional anesthesiologists adept at ultrasound techniques. To standardize image capture, patients were placed in the supine position, with the head of the bed inclined 45 degrees, and the neck rotated toward the nonoperative side. After aseptic skin preparation with chlorhexidine and sterile draping, an ultrasound examination was performed using an X-Porte (SonoSite, Bothell, WA, USA) with a linear HFL38, 6- to $13-\mathrm{MHz}$ ultrasound transducer, specifically observing the brachial plexus in the short-axis view. Images were captured in the following scanning sequence: (1) visualizing the brachial plexus at the supraclavicular level, (2) sliding the transducer proximally to the interscalene region to visualize the brachial plexus between anterior and middle scalene muscles, (3) sliding further proximally to view the cervical nerve roots entering neural foramina, and (4) sliding distally as the cervical nerve roots 
emerge between anterior and middle scalene muscles. Except for depth, which was adjusted to accommodate for patients' body habitus as necessary, ultrasound settings were standardized to ensure uniform quality and image capture. After the initial ultrasound examination was completed, a $30 \mathrm{~s}$ prospective video clip was recorded using the aforementioned scanning procedure to better recreate real-time experience of ISB block performance.

After media acquisition, patients received a preoperative ISB as part of a standardized multimodal pain regimen focusing on preemptive analgesia and opioid reduction. The potential of residual local anesthetic and its impact on postoperative ultrasound imaging was examined considerably during study design. An extensive literature search revealed no published data demonstrating the visual identification of residual local anesthetic at set time intervals following regional blockade. Our collective observation, however, is that local anesthetic dissipates quickly following injection through mechanisms of absorption and dissemination through facial planes. Additional measures were implemented during ISB to minimize the possibility of residual local anesthetic during postoperative ultrasound imaging. Specifically, the same regional anesthesiologist involved with the ultrasound examination also performed the ISB at least $1 \mathrm{~h}$ prior to surgery using a single-injection, peri-plexus technique under continuous live ultrasound guidance; a 22-gauge $50 \mathrm{~mm}$ Stimuplex needle (B. Braun, Bethlehem, PA, USA) was advanced via an out-of-plane approach to the posterolateral border of the interscalene groove, located between the middle scalene muscle and brachial plexus fascial sheath in a single needle pass. A total volume of 5 to $10 \mathrm{~mL}$ of $0.5 \%$ bupivacaine with $1: 200,000$ epinephrine was administered while observing appropriate local anesthetic spread within the interscalene groove, and no hydrolocalization (repeated injections of solution to help navigate needle tip to target site) was used.

Following arthroscopic shoulder surgery, patients underwent postoperative ultrasound scanning within 15-30 min of arriving in the post anesthesia care unit, using the same standardized methodology. All media were extracted from the ultrasound machine via an encrypted USB flash-drive and edited to remove identification information including patient clinic number, date, and time. Each video file was renamed to a number, assigned by a random number generator, and placed in a password protected digital folder. Study personnel maintained a confidential record of the original media files with the corresponding file numbers.

Reviewer Scoring System

Ultrasound Guidance for Interscalene Nerve Block

1) Visualization of Interscalene Brachial Plexus

Please circle one of the following

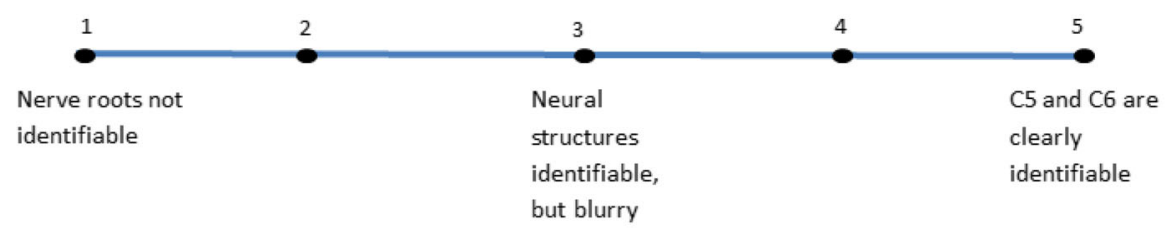

2) Confidence in Performing Interscalene Brachial Plexus Nerve Block

Please circle one of the following

\begin{tabular}{|c|c|c|}
\hline $\begin{array}{l}\text { Would not } \\
\text { attempt }\end{array}$ & $\begin{array}{l}\text { Would require significant } \\
\text { probe/needle manipulation; } \\
\text { combination techniques would be } \\
\text { considered (e.g. addition of nerve } \\
\text { stimulation) }\end{array}$ & $\begin{array}{l}\text { Straightforward using } \\
\text { ultrasound only, with } \\
\text { minimal probe/needle } \\
\text { manipulation }\end{array}$ \\
\hline
\end{tabular}

Fig. 1 Reviewer scoring system for pre- and postoperative ultrasound examination using five-point Likert scale 
Three fellowship-trained regional anesthesiologists with $>5$ years of staff experience, who were not involved with the process of obtaining ultrasound images nor performed ISB for study patients, independently reviewed the ultrasound media on a high-quality desktop monitor (HP Elite Display E242, Hewlett-Packard, Palo Alto, CA, USA) in a private area. These expert reviewers were blinded to patient information, the image acquisition process, and the timing of when videos were obtained (pre- or postoperatively). Similar to the methodology by Neuts et al. [9] and Stolz et al. [10], the reviewers assessed visualization of the brachial plexus and their confidence in performing ISB, from the collected media, using a five-point Likert scale (Fig. 1). Reviewers could pause, fast-forward, and rewind video clips during review, without a set time limit.

\section{Outcomes}

The objective of this study was to compare pre- versus post-surgical ultrasound imaging quality of the brachial plexus during arthroscopic shoulder surgery in patients receiving ISB. Primary outcomes evaluated include (a) observed differences in ultrasound image quality of the brachial plexus at the interscalene level and (b) differences in proceduralist' confidence performing ISB, given this imaging.

Our secondary outcome was to evaluate surgical or patient variables that could influence pre- and postoperative ultrasound image quality. Factors analyzed included age, gender, BMI, duration of surgery, obstructive sleep apnea (OSA), and volume of arthroscopic irrigation fluid.

\section{Sample size}

Since no prior data was available for the primary outcomes for this study, sample size calculations were performed using an effect size approach, where an effect size is defined as the difference in means divided by the standard deviation. The study was designed to have power to detect a medium effect size (i.e. an effect size of 0.5 to 0.8 ). Specifically, based on a paired t-test with alpha $=0.05$ (two-sided), a power analysis demonstrated that a sample of 30 subjects would provide $80 \%$ power to detect an effect size of 0.50 or larger as being statistically significant. To accommodate attrition of approximately $10 \%$ (due to canceled surgery, patient dropout, and other reasons), a total sample size 33 patients was chosen.

\section{Data analysis}

Data is reported using standard descriptive statistics, including means and standard deviations for continuous variables, and counts and percentages for categorical variables. The agreement between the 3 reviewers was
Table 1 Characteristics and surgical data of patients. Values are mean (SD) or number (proportion)

Total $(N=29)$

\begin{tabular}{|c|c|}
\hline & Total $(N=29$ \\
\hline \multicolumn{2}{|l|}{ Patient Age } \\
\hline Mean (SD) & $59.7(12.7)$ \\
\hline Median & 62.0 \\
\hline Range & $23.0,80.0$ \\
\hline \multicolumn{2}{|l|}{ Gender, n (\%) } \\
\hline Female & $13(44.8 \%)$ \\
\hline Male & $16(55.2 \%)$ \\
\hline \multicolumn{2}{|l|}{ BMI } \\
\hline Mean (SD) & $27.3(4.5)$ \\
\hline Median & 26.8 \\
\hline Range & $20.0,37.9$ \\
\hline \multicolumn{2}{|l|}{ BMI, n (\%) } \\
\hline Normal (18.5-24.9) & $10(34.5 \%)$ \\
\hline Overweight (25.0-29.9) & $13(44.8 \%)$ \\
\hline Obese $(\geq 30.0)$ & $6(20.7 \%)$ \\
\hline \multicolumn{2}{|l|}{ Diagnosis, n (\%) } \\
\hline Rotator Cuff Tear & $24(82.8 \%)$ \\
\hline Labral Tear & $2(6.9 \%)$ \\
\hline Rotator cuff tendonitis & $1(3.4 \%)$ \\
\hline Impingement & $1(3.4 \%)$ \\
\hline Pectoralis minor syndrome & $1(3.4 \%)$ \\
\hline \multicolumn{2}{|l|}{ Side of Surgery, $n(\%)$} \\
\hline Left & $15(51.7 \%)$ \\
\hline Right & $14(48.3 \%)$ \\
\hline \multicolumn{2}{|l|}{ STOP-BANG Total Score, $\mathrm{n}(\%)$} \\
\hline 0 to 2 (Low risk) & $18(62.1 \%)$ \\
\hline 3 to 4 (Intermediate Risk) & $5(17.2 \%)$ \\
\hline$\geq 5$ (High risk) & $1(3.4 \%)$ \\
\hline Confirmed diagnosis of obstructive sleep apnea & $5(17.2 \%)$ \\
\hline \multicolumn{2}{|l|}{ ASA score, $n(\%)$} \\
\hline 1 & $1(3.4 \%)$ \\
\hline 2 & $23(79.3 \%)$ \\
\hline 3 & $5(17.2 \%)$ \\
\hline \multicolumn{2}{|l|}{ Number of irrigation bags } \\
\hline Mean (SD) & $7.2(3.7)$ \\
\hline Median & 6.0 \\
\hline Range & $4.0,20.0$ \\
\hline \multicolumn{2}{|l|}{ Total irrigation Vol (liters) } \\
\hline Mean (SD) & $21.5(11.0)$ \\
\hline Median & 18.0 \\
\hline Range & $12.0,60.0$ \\
\hline \multicolumn{2}{|l|}{ Procedure Duration (mins) } \\
\hline Mean (SD) & $81.2(37.7)$ \\
\hline Median & 72.0 \\
\hline Range & $24.0,162.0$ \\
\hline
\end{tabular}


Table 2 Individual reviewer and aggregate scores for pre- and postoperative ultrasound examination of brachial plexus

\begin{tabular}{|c|c|c|c|c|c|c|}
\hline & & & Mean & Mean & Mean & \\
\hline & Reviewer & $\mathbf{N}$ & Pre-op & Post-op & Difference & $p$-value \\
\hline \multirow[t]{4}{*}{ Quality of ultrasound visualization } & 1 & 29 & 4.4 & 3.7 & -0.7 & 0.006 \\
\hline & 2 & 29 & 4.7 & 3.9 & -0.8 & $<0.001$ \\
\hline & 3 & 29 & 4.5 & 3.8 & -0.8 & $<0.001$ \\
\hline & Aggregate Mean & 29 & 4.5 & 3.8 & -0.7 & $<0.001$ \\
\hline \multirow[t]{4}{*}{ Confidence in performing ISB } & 1 & 29 & 4.8 & 4.1 & -0.8 & $<0.001$ \\
\hline & 2 & 29 & 4.9 & 4.2 & -0.7 & $<0.001$ \\
\hline & 3 & 29 & 4.8 & 4.3 & -0.5 & 0.009 \\
\hline & Aggregate Mean & 29 & 4.8 & 4.2 & -0.7 & $<0.001$ \\
\hline
\end{tabular}

ISB Interscalene nerve block

analyzed using Fleiss's Kappa statistic, and separate analyses were performed for each question for the preoperative data and the postoperative data. Comparisons of the reviewers' ratings between the preoperative and postoperative periods were performed using Wilcoxon signedrank tests; separate comparisons were performed for each reviewer, and for the average ratings of all 3 reviewers. The association of demographic and surgical factors with the reviewers' ratings was analyzed using general linear models utilizing generalized estimating equations (GEE) to account for the within-subject correlation due to the study design in which each reviewer evaluated the same set of patient data. All statistical tests were two-sided and $p$-values less than 0.05 were considered significant. The analyses were conducted using SAS version 9.4 M6 (SAS Institute Inc., Cary, NC, USA) and $\mathrm{R}$ version 3.6.2 (R Foundation for Statistical Computing, Vienna, Austria).

\section{Results}

Between June 2018 and November 2018, 33 patients undergoing elective, unilateral shoulder arthroscopy were enrolled into the study. Of the 33 patients, data from four patients were excluded due to conversion from arthroscopy to open surgical repair during the operation. A final sample size of 29 patients was used for data analysis, which according to our estimations provides $80 \%$ power to detect an effect size difference of 0.54 or larger (medium effect).

Demographics are displayed in Table 1. A majority of the patients underwent shoulder arthroscopy for rotator cuff repair (83\%). The mean body mass index was 27.3 (Range: 20-37.9), and 11 of 29 patients had a diagnosis of OSA or were at intermediate to high risk for OSA per STOP-BANG criteria [11]. Average procedure duration was $81.2 \mathrm{~min}$ (Range: 24-162), and the mean irrigation volume used during shoulder arthroscopy was 21.51 (Range: 12-60 l).

Aggregate preoperative mean scores in quality of ultrasound visualization were significantly higher than postoperative scores (preoperative mean 4.5 vs postoperative mean $3.8 ; p<.001$ ), as was confidence in performing blockade based on the preoperative study (preoperative mean 4.8 vs postoperative mean

Table 3 Comparison across reviewers for pre- and postoperative quality of ultrasound visualization and confidence in performing ISB. Values are mean (SD)

\begin{tabular}{|c|c|c|c|c|c|c|}
\hline & & $\mathrm{R}^{\mathrm{a}}(N=29)$ & $\mathrm{R}^{\mathrm{a}}(N=29)$ & $\mathrm{R3}^{\mathrm{a}}(N=29)$ & Total $(N=87)$ & $p$-value \\
\hline \multicolumn{7}{|c|}{ Quality of ultrasound visualization } \\
\hline \multirow[t]{2}{*}{ Pre-op } & Mean (SD) & $4.4(0.7)$ & $4.70(0.5)$ & $4.5(0.5)$ & $4.5(0.6)$ & 0.218 \\
\hline & Range & $3.0-5.0$ & $3.0-5.0$ & $4.0-5.0$ & $3.0-5.0$ & \\
\hline \multirow[t]{2}{*}{ Post-op } & Mean (SD) & $3.7(0.9)$ & $3.9(0.8)$ & $3.8(0.9)$ & $3.8(0.9)$ & 0.721 \\
\hline & Range & $3.0-5.0$ & $3.0-5.0$ & $2.0-5.0$ & $2.0-5.0$ & \\
\hline \multicolumn{7}{|c|}{ Confidence in performing ISB } \\
\hline \multirow[t]{2}{*}{ Pre-op } & Mean (SD) & $4.8(0.384)$ & $4.9(0.4)$ & $4.8(0.4)$ & $4.8(0.4)$ & 0.444 \\
\hline & Range & $4.0-5.0$ & $3.0-5.0$ & $4.0-5.0$ & $3.0-5.0$ & \\
\hline \multirow[t]{2}{*}{ Post-op } & Mean (SD) & $4.1(1.0)$ & $4.2(0.8)$ & $4.3(0.8)$ & $4.2(0.9)$ & 0.657 \\
\hline & Range & $3.0-5.0$ & $3.0-5.0$ & $3.0-5.0$ & $3.0-5.0$ & \\
\hline
\end{tabular}

ISB Interscalene nerve block

${ }^{\mathrm{a}} \mathrm{R} 1, \mathrm{R} 2, \mathrm{R} 3$ refers to Reviewers 1,2 , and 3 respectively 
Table 4 (A-D) Regression analysis of pre-defined variables during pre- and postoperative ultrasound examination

\begin{tabular}{|c|c|c|}
\hline & Parameter estimate & $p$-value \\
\hline \multicolumn{3}{|c|}{ A) Pre-op, ultrasound visualization } \\
\hline (Intercept) & 4.814 & \\
\hline Age & 0.001 & 0.841 \\
\hline Female vs Male & -0.090 & 0.546 \\
\hline Obese vs Normal ${ }^{a}$ & -0.524 & 0.022 \\
\hline Overweight vs Normal ${ }^{a}$ & -0.433 & 0.009 \\
\hline \multicolumn{3}{|c|}{ B) Post-op, ultrasound visualization } \\
\hline (Intercept) & 4.458 & \\
\hline Age & 0.003 & 0.772 \\
\hline Female vs Male & -0.236 & 0.431 \\
\hline Obese vs Normal ${ }^{a}$ & -0.358 & 0.320 \\
\hline Overweight vs Normal ${ }^{a}$ & -0.135 & 0.627 \\
\hline Duration (per $10 \mathrm{~min}$ ) & -0.086 & 0.051 \\
\hline Fluid (per liter) & 0.005 & 0.668 \\
\hline \multicolumn{3}{|l|}{ C) Pre-op, Confidence in ISB } \\
\hline (Intercept) & 5.186 & \\
\hline Age & -0.004 & 0.158 \\
\hline Female vs Male & -0.179 & 0.089 \\
\hline Obese vs Normal ${ }^{a}$ & -0.293 & 0.140 \\
\hline Overweight vs ${ }^{a}$ Normal & -0.017 & 0.800 \\
\hline \multicolumn{3}{|l|}{ D) Post-op, Confidence in ISB } \\
\hline (Intercept) & 5.666 & \\
\hline Age & -0.011 & 0.355 \\
\hline Female vs Male & -0.399 & 0.215 \\
\hline Obese vs Normal ${ }^{\mathrm{a}}$ & -0.405 & 0.372 \\
\hline Overweight vs ${ }^{a}$ Normal & -0.276 & 0.385 \\
\hline Duration (per $10 \mathrm{~min}$ ) & -0.051 & 0.329 \\
\hline Fluid (per liter) & -0.004 & 0.814 \\
\hline
\end{tabular}

ISB Interscalene nerve block

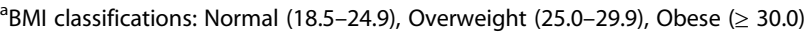

$4.2 ; p<.001$ ) (Table 2). Comparisons of mean scores across the three reviewers demonstrate similar values with no statistical difference for pre- and postoperative quality of ultrasound visualization and confidence in performing ISB (Table 3). Inter-rater reliability displayed fair to good consistency among the reviewers for ultrasound brachial plexus visualization (pre-op: kappa 0.32, $p<0.001$; post-op: kappa $0.41, p<0.001)$, and confidence in block performance (pre-op: kappa $0.08, p=.45$; post-op: kappa $0.50, p<0.001)$.

Regression and subgroup analyses were performed for pre-defined variables which may impact ultrasound visualization and confidence in performing ISB (Table 4A, B, C, and D). High patient BMI negatively affected ultrasound visualization of the brachial plexus in the preoperative period ( $p<0.05$ for both weight categories; Table 4A). Patients with intermediate to high risk or confirmed OSA displayed lower aggregate postoperative mean scores in comparison to patients with low-risk OSA for both image quality ( 3.4 vs $4.0 ; p<.05)$ and confidence in performing ISB (3.8 vs $4.4 ; p<.05)$ (Table 5). Although the intermediate to high risk or confirmed OSA group had a larger difference in aggregate mean scores compared to low-risk OSA for both outcomes, this was not statistically significant.

\section{Discussion}

The results of our investigation demonstrate that, in expert hands, ultrasound visualization of the brachial plexus and confidence in performing ISB was superior with imaging performed before surgery compared to the postoperative period in patients undergoing arthroscopic surgery of the shoulder. Though further studies are required, our results seem to indicate that the consistent use of preoperative ISB for shoulder arthroscopy may confer benefits of improved efficacy and safety when compared to postoperative block placement.

In addition, our findings show lower ultrasound image quality in obese patients compared to patients of lower body mass index, regardless of block timing. Numerous other investigations have similarly demonstrated poor visualization of peripheral nerves in obese patients, attributed to scattering of ultrasound waves in adipose tissue and greater depth required for imaging, which may compromise the sonographer's ability to delineate the neurologic structures at the interscalene level [12-14]. Similarly, patients with OSA or those with intermediate-high risk of OSA had lower postoperative mean scores and larger differences in mean scores for both ultrasound visualization and confidence in block performance.

Although the results from our reviewers show a decrement in ultrasound imaging quality of the brachial plexus and decreased confidence in performing ISB, postoperative regression analysis did not show a statistical relationship to other secondary outcomes studied: age, gender, BMI, duration of surgery and volume of arthroscopic irrigation fluid. This lack of association with regard to irrigation fluid may be due to the sample size of the study, or that patients may vary widely in the degree of tissue extravasation, which may occur based on other demographic and/or surgical factors. Fluid extravasation from the shoulder compartment and subsequent absorption into adjacent soft tissue is a welldocumented phenomenon in arthroscopic shoulder surgery. This has been associated with a number of possible complications, including severe head and neck swelling, airway compromise, prolonged intubation, and increased deltoid muscle compartment pressures from tissue edema [15-18]. Surgical risk factors accounting for fluid 
Table 5 Sub-group analysis evaluating patients with low risk OSA and diagnosis of OSA or intermediate to high risk OSA

\begin{tabular}{|c|c|c|c|c|}
\hline & & \multicolumn{2}{|c|}{ Obstructive sleep apnea } & \multirow[b]{2}{*}{$\begin{array}{l}\text { Low-risk vs Intermediate/High risk/ } \\
\text { confirmed OSA }_{p \text {-value }}{ }^{\mathrm{a}}\end{array}$} \\
\hline & & $\begin{array}{l}\text { Low-risk OSA } \\
(N=18)\end{array}$ & $\begin{array}{l}\text { Intermediate/High risk/ } \\
\text { confirmed OSA }(N=11)\end{array}$ & \\
\hline \multirow{6}{*}{$\begin{array}{l}\text { Quality of ultrasound } \\
\text { visualization }\end{array}$} & Pre-Op & & & \\
\hline & Aggregate Mean (SD) & $4.6(0.44)$ & $4.5(0.52)$ & 0.642 \\
\hline & Post-Op & & & \\
\hline & Aggregate Mean (SD) & $4.0(0.70)$ & $3.4(0.71)$ & 0.027 \\
\hline & $\begin{array}{l}\text { Pre-op vs Post-op } \\
p \text {-value }\end{array}$ & 0.016 & 0.004 & \\
\hline & $\begin{array}{l}\text { Aggregate Mean } \\
\text { Difference (SD) }\end{array}$ & $-0.5(0.89)$ & $-1.1(0.76)$ & 0.087 \\
\hline \multirow{6}{*}{$\begin{array}{l}\text { Confidence in } \\
\text { performing ISB }\end{array}$} & Pre-Op & & & \\
\hline & Aggregate Mean $(S D)^{b}$ & $4.9(0.16)$ & $4.7(0.42)$ & 0.242 \\
\hline & Post-Op & & & \\
\hline & Aggregate Mean (SD) & $4.4(0.73)$ & $3.8(0.75)$ & 0.028 \\
\hline & $\begin{array}{l}\text { Pre-op vs Post-op } \\
p \text {-value }\end{array}$ & 0.016 & 0.004 & \\
\hline & $\begin{array}{l}\text { Aggregate Mean } \\
\text { Difference (SD) }\end{array}$ & $-0.5(0.72)$ & $-1.0(0.71)$ & 0.076 \\
\hline
\end{tabular}

OSA Obstructive Sleep Apnea, ISB Interscalene nerve block

anequal variance two sample t-test

${ }^{\mathrm{b}}$ Aggregate mean of scores from Reviewers 1 to 3

extravasation from the protective barrier of the glenohumeral capsule include prolonged procedure times, large volume of irrigation fluid, fluid pressures above $150 \mathrm{mmHg}$, use of automated pump systems, and anatomical abnormalities resulting in pathological tears or lesions in adjacent musculature [18, 19].

Consequently, mobilization of irrigation fluid between tissue planes in the head and neck may degrade ultrasound imaging of neurovascular structures, a phenomenon described as layer non-differentiation. Studies have demonstrated that tissue edema, leading to layer non-differentiation, had the highest odds ratio of predicting poor image quality amongst several studied artifacts known to compromise ultrasound imaging, which could explain our findings [20]. These risk factors may present a challenge for anesthesiologists attempting to stratify and predict patients with significant tissue edema postoperatively (the attached movie files show an ultrasound scan of the same patient before (Additional file 1) and after (Additional file 2) arthroscopic shoulder surgery. In "Additional file 2", greater ultrasound depth was required to facilitate imaging of the brachial plexus due to tissue edema.

Previous investigations have highlighted numerous clinical advantages in performing ISB pre- versus postoperatively during shoulder arthroscopy. First, pre-emptive regional anesthesia techniques integrated into a multimodal analgesic pathway for orthopedic surgery have shown to improve perioperative outcomes, including reduced opioid consumption, improved hospital discharge times and increased patient satisfaction [7]. Moreover, use of preoperative blockade can provide intraoperative hemodynamic stability and improved surgical visualization without concomitant use of neuromuscular blockade under general anesthesia [21-23]. Lastly, the posterior cervical triangle contains important neurovascular structures (e.g. phrenic nerve, branches of subclavian artery) that are subject to potential injury during ISB and require optimal ultrasound imaging to improve block safety.

Considering all these factors in addition to our findings, preoperative performance of ISB for arthroscopic shoulder surgery may confer advantages in both efficacy and safety, since optimal ultrasound visualization enables providers to clearly differentiate neurologic targets from structures to be avoided. Certainly, we cannot draw direct conclusions among patients who experience clinically significant fluid extravasation and tissue edema, but it is logical that image quality degradation during an ultrasound-guided regional technique would decrease its efficacy and safety, especially over larger cohorts of patients in a common surgical procedure.

There are several limitations to this study. First, generalizability of our findings is limited to arthroscopic shoulder procedures; as such, the findings of our study cannot be extrapolated to other surgical procedures, such as shoulder arthroplasty. Second, we did not collect arthroscopic irrigation pressures, which could influence fluid extravasation postoperatively. However, this 
variable is difficult to collect accurately because the surgical team frequently adjusts pressures to maintain consistent field visualization. Third, residual local anesthetic injectate during postoperative ultrasound examination could be present. However, we strongly believe the likelihood is low for several reasons: a large interval between pre- and postoperative examination was intentionally devised to allow adequate time for local anesthetic absorption and fascial spread, a low volume of local anesthetic was utilized, and deposition of fluid adjacent to nerve roots create a tissue-fluid interface, thereby enhancing ultrasound visualization of neural tissue (sonographic accentuation of nerves against a hypoechoic background of fluid) [24-26], which consequently would improve reviewers' postoperative ultrasound examination scores (contrary to our study findings). Lastly, convenience sampling and the subjective nature of the grading scales could increase the risk of bias. Although acquisition of the ultrasound images and video clips were standardized and blinded to the reviewers, these were recorded media files that relied on consistent ultrasound settings (depth, gain, etc.) from the proceduralist. This may impact the quality and interpretation of the brachial plexus imaging since reviewers did not perform dynamic ultrasound imaging. In addition, it is unknown if statistically significant differences in our results, comparing pre- vs. postoperative Likert scoring, are associated with clinically meaningful differences in block performance and success rates.

In conclusion, the effects of arthroscopic shoulder surgery on head and neck sonoanatomy should not be overlooked. The findings of our study demonstrate superior visualization and greater block confidence associated with preoperative ultrasound imaging of the interscalene brachial plexus in expert hands, compared to postoperative ultrasound imaging at the same level. This is particularly apparent in those with previously diagnosed OSA, or those who are intermediate-high risk of OSA per STOP-BANG stratification. Given the potential benefits of preoperative blockade on patient outcomes and pre-emptive multimodal analgesia, as well as the potential risks associated with postoperative blockade, we advocate for use of preoperative ISB for arthroscopic shoulder surgery when feasible. Further investigations are needed to corroborate these findings in a larger cohort and to identify patient and/or surgical-related factors, which may be modifiable, associated with tissue edema during arthroscopic shoulder surgery, specifically in practices where postoperative block performance is frequently utilized.

\section{Abbreviations}

ISB: Interscalene nerve block; PACU: Post-anesthesia care unit; STROBE: Strengthening the Reporting of Observational studies in Epidemiology; GEE: Generalized estimating equations

\section{Supplementary Information}

The online version contains supplementary material available at https://doi. org/10.1186/s12871-021-01409-3.

Additional file 1. Preoperative Ultrasound Scan Video for Patient X. Description - ultrasound evaluation of interscalene brachial plexus prior to surgery displaying clear visualization of C5 and C5 nerve roots.

Additional file 2. Postoperative Ultrasound Scan Video for Patient X. Description - ultrasound evaluation of interscalene brachial plexus after shoulder arthroscopy displaying significant soft tissue edema and blurry visualization of $\mathrm{C} 5$ and $\mathrm{C} 6$ nerve roots.

\section{Acknowledgements}

The authors would like to thank Drs. Chris Duncan and Adam Jacob for their participation as reviewers in this study, as well as Mr. Dirk Larson for aiding in statistical analysis.

\section{Authors' contributions}

$J P, R J, B P, A A, J S S, D M$, and HS participated in the design, execution, and/or analysis of the work presented, and attests to the accuracy and validity of the contents. All authors read and approved the final manuscript.

\section{Authors' information}

Not applicable.

\section{Funding}

Internal Funding through the Department of Anesthesiology, Mayo Clinic, Rochester, MN, USA.

\section{Availability of data and materials}

All data generated or analysed during this study are included in this published article.

\section{Declarations}

Ethics approval and consent to participate

This study was approved by our Institutional Review Board (No. 18-004131, Mayo Clinic, Rochester, MN, USA) and was registered at ClinicalTrials.gov (NCT03657173). All patients provided written informed consent to participate, and this study was completed in accordance with the Strengthening the Reporting of Observational studies in Epidemiology (STROBE) guidelines,

\section{Consent for publication}

Not applicable.

\section{Competing interests}

The authors declare that they have no competing interests. Dr. SanchezSotelo reports personal fees from Consultant for Wright, grants and personal fees from Stryker Royalties, personal fees from Consultant for Exactech, other from PrecisionOS, personal fees from Journal Editor for Journal of Shoulder and Elbow Surgery, other from PSI, personal fees from Elsevier, personal fees from Oxford University Press. All disclosures do not compete with this investigation, are outside the submitted work, and do not influence the results and/or discussion reported in this paper.

\section{Author details}

'Department of Anesthesiology and Perioperative Medicine, Mayo Clinic, 200 First St SW, Rochester, MN 55905, USA. ${ }^{2}$ Department of Anesthesiology and Perioperative Medicine, Mayo Clinic Health System, Mankato, MN, USA.

${ }^{3}$ Department of Orthopedic Surgery, Mayo Clinic, Rochester, MN, USA.

Received: 16 January 2021 Accepted: 23 June 2021

Published online: 09 July 2021

\section{References}

1. Panchamia JK, Amundson AW, Jacob AK, Sviggum HP, Nguyen NTV, Sanchez-Sotelo J, et al. A 3-arm randomized clinical trial comparing interscalene blockade techniques with local infiltration analgesia for total 
shoulder arthroplasty. J Shoulder Elb Surg. 2019;28(10):e325-38. https://doi. org/10.1016/j.jse.2019.05.013

2. Yan S, Zhao Y, Zhang H. Efficacy and safety of interscalene block combined with general anesthesia for arthroscopic shoulder surgery: a meta-analysis. J Clin Anesth. 2018;47:74-9. https://doi.org/10.1016/j.jclinane.2018.03.008.

3. Chellam S, Chiplonkar S, Pathak K. Change in neck circumference after shoulder arthroscopy: an observational study. Indian J Anaesth. 2015;59(6): 365-8. https://doi.org/10.4103/0019-5049.158742.

4. Cohen JM, Gray AT. Functional deficits after intraneural injection during interscalene block. Reg Anesth Pain Med. 2010;35(4):397-9. https://doi.org/1 0.1097/AAP.0b013e3181e8a35f

5. Panchamia JK, Olsen DA, Amundson AW. Unique phrenic nerve-sparing regional anesthetic technique for pain management after shoulder surgery. Case Rep Anesthesiol. 2017;2017:1294913.

6. Montoro E, Ferre F, Yonis H, Gris C, Minville V. Pneumothorax as a complication of ultrasound-guided interscalene block for shoulder surgery. Eur J Anaesthesiol. 2013;30(2):90-1. https://doi.org/10.1097/EJA.0b013e3283 564714

7. Hebl JR, Dilger JA, Byer DE, Kopp SL, Stevens SR, Pagnano MW, et al. A preemptive multimodal pathway featuring peripheral nerve block improves perioperative outcomes after major orthopedic surgery. Reg Anesth Pain Med. 2008;33(6):510-7. https://doi.org/10.1097/00115550-200811000-00002.

8. von Elm E, Altman DG, Egger M, Pocock SJ, Gotzsche PC, Vandenbroucke $J P$, et al. The Strengthening the Reporting of Observational Studies in Epidemiology (STROBE) statement: guidelines for reporting observational studies. Lancet. 2007;370(9596):1453-7. https://doi.org/10.1016/S0140-673 6(07)61602-X.

9. Neuts A, Stessel B, Wouters PF, Dierickx C, Cools W, Ory JP, et al. Selective suprascapular and axillary nerve block versus interscalene plexus block for pain control after arthroscopic shoulder surgery: a noninferiority randomized parallel-controlled clinical trial. Reg Anesth Pain Med. 2018; 43(7):738-44. https://doi.org/10.1097/AAP.0000000000000777.

10. Stolz LA, Acuna JG, Gaskin K, Murphy AM, Friedman L, Stears-Ellis S, et al. Echogenicity and ultrasound visibility of peripheral nerves of the upper extremity. Med Ultrason. 2018;20(2):199-204. https://doi.org/10.11152/ mu-1240.

11. Chung F, Yegneswaran B, Liao P, Chung SA, Vairavanathan S, Islam S, et al. STOP questionnaire: a tool to screen patients for obstructive sleep apnea. Anesthesiology. 2008;108(5):812-21. https://doi.org/10.1097/ALN.0b013e31 816d83e4.

12. Hanouz JL, Grandin W, Lesage A, Oriot G, Bonnieux D, Gerard JL. Multiple injection axillary brachial plexus block: influence of obesity on failure rate and incidence of acute complications. Anesth Analg. 2010;111(1):230-3. https://doi.org/10.1213/ANE.0b013e3181dde023.

13. Schroeder K, Andrei AC, Furlong MJ, Donnelly MJ, Han S, Becker AM. The perioperative effect of increased body mass index on peripheral nerve blockade: an analysis of 528 ultrasound guided interscalene blocks. Rev Bras Anestesiol. 2012;62(1):28-38. https://doi.org/10.1016/50034-7094(12)70100-9.

14. Ingrande J, Brodsky JB, Lemmens HJ. Regional anesthesia and obesity. Cur Opin Anaesthesiol. 2009;22(5):683-6. https://doi.org/10.1097/ACO.0b013e32 832eb7bd.

15. Vier BR, Mombell KW, Gagliano EL, King NM, McDonald LS. Extravasation of fluid in arthroscopic shoulder surgery requiring prolonged intubation: a case report. Patient Saf Surg. 2019;13(1):21. https://doi.org/10.1186/s13037019-0202-8.

16. Orebaugh SL. Life-threatening airway edema resulting from prolonged shoulder arthroscopy. Anesthesiology. 2003;99(6):1456-8. https://doi.org/1 0.1097/00000542-200312000-00034

17. Blumenthal S, Nadig M, Gerber C, Borgeat A. Severe airway obstruction during arthroscopic shoulder surgery. Anesthesiology. 2003;99(6):1455-6. https://doi.org/10.1097/00000542-200312000-00033.

18. Memon M, Kay J, Gholami A, Simunovic N, Ayeni OR. Fluid extravasation in shoulder arthroscopic surgery: a systematic review. Orthop J Sports Med. 2018;6(5):2325967118771616. https://doi.org/10.1177/2325967118771616.

19. Catal B, Azboy I. Fluid retention after shoulder arthroscopy: gravity flow vs automated pump-a prospective randomized study. J Shoulder Elb Surg. 2019;28(10):1911-7. https://doi.org/10.1016/j.jse.2019.05.041.

20. Burk RS, Grap MJ, Lucas V, Munro CL, Wetzel PA, Schubert CM. Highfrequency ultrasound: obtaining optimal images and the effect of image artifacts on image quality. Adv Wound Care (New Rochelle). 2017:6(11):38391. https://doi.org/10.1089/wound.2017.0727.
21. Bosco L, Zhou C, Murdoch JAC, Bicknell R, Hopman WM, Phelan R, et al. Pre- or postoperative interscalene block and/or general anesthesia for arthroscopic shoulder surgery: a retrospective observational study. Can J Anaesth. 2017;64(10):1048-58. https://doi.org/10.1007/s12630-017-0937-6.

22. Brown AR, Weiss R, Greenberg C, Flatow EL, Bigliani LU. Interscalene block for shoulder arthroscopy: comparison with general anesthesia. Arthroscopy. 1993;9(3):295-300. https://doi.org/10.1016/S0749-8063(05)80425-6.

23. Choi S, Kim T, Kwon YS, Kang H. Intra-operative effect of interscalene brachial plexus block to arthroscopic rotator cuff repair surgery. Int Orthop. 2019;43(9):2117-24. https://doi.org/10.1007/s00264-018-4199-x.

24. Karmakar MK, Ho AM, Li X, Kwok WH, Tsang K, Ngan Kee WD. Ultrasoundguided lumbar plexus block through the acoustic window of the lumbar ultrasound trident. Br J Anaesth. 2008;100(4):533-7. https://doi.org/10.1093/ bja/aen026

25. Karmakar MK, Shariat AN, Pangthipampai P, Chen J. High-definition ultrasound imaging defines the paraneural sheath and the fascial compartments surrounding the sciatic nerve at the popliteal fossa. Reg Anesth Pain Med. 2013;38(5):447-51. https://doi.org/10.1097/AAP.0b013e31 $829 f f c b 4$.

26. Gray AT. Ultrasound-guided regional anesthesia: current state of the art. Anesthesiology. 2006;104(2):368-73 discussion 365A.

\section{Publisher's Note}

Springer Nature remains neutral with regard to jurisdictional claims in published maps and institutional affiliations.
Ready to submit your research? Choose BMC and benefit from:

- fast, convenient online submission

- thorough peer review by experienced researchers in your field

- rapid publication on acceptance

- support for research data, including large and complex data types

- gold Open Access which fosters wider collaboration and increased citations

- maximum visibility for your research: over $100 \mathrm{M}$ website views per year

At $\mathrm{BMC}$, research is always in progress.

Learn more biomedcentral.com/submissions 